\title{
Electrochemical and Economic Evaluation of the Cocoa Bean Shell as a Corrosion Inhibitor in Acidic Medium
}

\author{
Mayara Cristina Fernandes de Carvalho ${ }^{a} \mathbb{D}^{\text {, }}$, Nayara Maria Santos de Almeida ${ }^{a}$ (1),

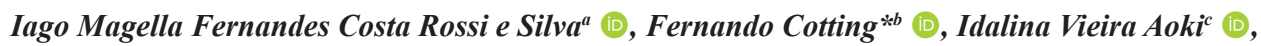 \\ Vera Rosa Capelossi $i^{a}$
}

${ }^{a}$ Universidade Estadual de Santa Cruz, Departamento de Ciência e Tecnologia Exata, CEP 45662-900, Ilhéus, BA, Brasil.

${ }^{b}$ Universidade Federal de Minas Gerais, Departamento de Engenharia Quimica, Av. Antonio Carlos,6627, CEP 31270-901, Belo Horizonte, MG, Brazil. 'Universidade de São Paulo, Escola Politécnica, Departamento de Engenharia Química Av. Luciano Gualberto, travessa 3, 380, CEP 05508-010, São Paulo, SP, Brazil

Received: March 12, 2021; Revised: August 23, 2021; Accepted: November 29, 2021

The inhibition effect of the cocoa bean shell powder (CBSP) on SAE 1008 carbon steel was studied in acidic medium $\left(\mathrm{HCl} 0.5 \mathrm{~mol} \mathrm{~L}^{-1}\right)$ by electrochemical techniques and gravimetric measurements. Fourier Transform Infrared Spectroscopy (FTIR) and Scanning Electron Microscopy (SEM) were used to the chemical and morphological characterization. The gravimetric and EIS results showed that the corrosion rate decreases with increasing inhibitor concentration, reaching the maximum value of $97.92 \%$ in $1.77 \mathrm{~g} \mathrm{~L}^{-1}$ inhibitor (highest concentration studied). Even at the lowest concentration $\left(0.44 \mathrm{~g} \mathrm{~L}^{-1}\right)$ good corrosion inhibition efficiency $(96.03 \%)$ was observed. The polarization curves indicated that the CBSP acts as a mixed type inhibitor. The inhibitory molecules adsorption followed the Langmuir isotherm model. The inhibitor economic evaluation showed that the use of CBSP is 48-616 times cheaper than traditional inhibitors. The results showed that CBSP is an efficient corrosion inhibitor for carbon steel and its production is financially attractive.

Keywords: Carbon Steel, Cocoa bean shell, Natural Corrosion Inhibitor, EIS, SVET.

\section{Introduction}

The corrosion inhibitors are frequently employed in transports, storage, and manufacturing processes, as in the oil and gas industry, during acid cleaning of heat exchangers systems, and in the fuel storage tanks $\mathrm{s}^{1-2}$. Usually, corrosion inhibitors adsorb on the metallic surfaces, forming a protective layer $^{3}$. Therefore, the corrosion process can be reduced by decreasing the anodic and cathodic activities, or both; hindering the ionic mobility to the metallic surfaces, and increasing the electrical resistance of the metallic surface.

Since most of the metals have low corrosion resistance in acidic media, there is a constant search for corrosion inhibitors in these conditions ${ }^{2,4-5}$. Also, many studies employed carbon steel as a substrate due to its low cost and excellent mechanical properties in different areas of engineering. A lot of synthetic inhibitors have good anti-corrosion properties, but they are harmful and expensive ${ }^{5}$. On the other hand, natural inhibitors can often compete with either the food ${ }^{4}$ or the pharmaceutical industry ${ }^{6-7}$. Table 1 presents the main commercial substances and their respective inhibition efficiencies, for carbon steel in $\mathrm{HCl}$ solution at $25^{\circ} \mathrm{C}^{7-10}$.

Thus, in recent years, the study of corrosion inhibitors from natural products, which are environmentally friendly

*e-mail: fernando@deq.ufmg.br and have a low cost, has been growing in the form of extracts from different parts of plants ${ }^{2}$. The inhibitory properties associated with green inhibitors are related to the presence of compounds such as flavonoids, carotenoids, alkaloids, polyphenols, and other natural organic components that have nitrogen, oxygen, and sulfur atoms in their molecular structure $^{11}$.

In the literature, several studies reported the high efficiency of green corrosion inhibitors in the protection of carbon steel in acidic media, some examples include the use of extracts obtained through industrial processing residues: mango and orange pee ${ }^{11}$, barley agro-industrial residues ${ }^{1}$, cacao pod husk ${ }^{12-14}$ and peel garlic ${ }^{15}$. Nevertheless, to the best of our knowledge, no studies have been conducted on the economic evaluation between the green corrosion inhibitors and commercial substances.

Normally, natural inhibitors are obtained through natural product extraction procedures ${ }^{2}$. However, Santos et al. (2017) reported a different way to obtain a natural inhibitor ${ }^{16}$. The methodology used by them relates to the use of the residue in its powder form, in which only the cleaning, drying and fragmentation of the natural product was carried out (the dried material was milled and sieved to above 170 mesh). Therefore, Santos et al. (2017) investigated the anticorrosive 
action of castor bark powder when applied to 1020 carbon steel in $0.5 \mathrm{~mol} \mathrm{~L}^{-1} \mathrm{HCl}$ solution. The maximum efficiency achieved was $83 \%{ }^{16}$.

In the southern region of Bahia-Brazil, where chocolate is processed, a batch of waste by-products is produced during the industrial chocolate processing. These residues include the Theobroma cacao (cocoa) pod husk and the cocoa bean shell (the peels that involve the cocoa beans). The cocoa pod (also called cacao peel) is generated in a greater proportion, resulting from the breaking of the fruits for the extraction of the seeds ${ }^{13,17-18}$. In processing the seeds are fermented and dried and are then called cocoa beans. Commonly, the cocoa shells are separated from the bean after the roasting step (stage after fermentation) present in the chocolate production process ${ }^{18-20}$. This residue constitutes $10 \%-17 \%$ of the total weight of the cocoa bean ${ }^{21}$. Figure 1 shows these cocoa residues.

Some studies have shown the use of the cocoa pod as a corrosion inhibitor. Pedroza-Periñán et al. (2016) investigated the inhibitory effect of ethanol extracts from cocoa pod on A36 steel in $\mathrm{HCl} 1.0 \mathrm{~mol} \mathrm{~L}^{-1}$. In this study, $91.13 \%$ of the corrosion inhibition efficiency of carbon steel was identified through the extract obtained with $16.1 \% \mathrm{v} / \mathrm{v}$ ethanol. This anticorrosive activity was justified by the presence of phenols and tannins in the extract ${ }^{13}$. Barreto et al. (2017) also evaluated the ethanolic extract of the cocoa pod in the corrosion of the 1020 carbon steel in $0.5 \mathrm{~mol} \mathrm{~L}^{-1} \mathrm{HCl}$ solution $^{15}$. Through the gravimetric results, the maximum inhibition efficiency reached was $93 \%$ at a concentration of extract $1.112 \mathrm{~mol} \mathrm{~L}^{-115}$.

Table 1. Concentration and efficiency of commercial corrosion inhibitors for carbon steel in $\mathrm{HCl}$ media.

\begin{tabular}{ccc}
\hline Compound & $\begin{array}{c}\text { Concentration } \\
\left(\mathrm{g} \mathrm{L}^{-1}\right)\end{array}$ & Efficiency (\%) \\
\hline Pyrazolone & 0.90 & 78.0 \\
\hline Benzethonium chloride & 0.16 & 92.3 \\
\hline Benzotriazole & 0.30 & 90.0 \\
\hline Benzothiazole & 0.40 & 94.0 \\
\hline Dibenzylthiourea & 0.05 & 90.0 \\
\hline
\end{tabular}

Given this context, a new source for corrosion inhibitor can be found through the other cocoa residue, that is to say, the cocoa bean shell. Electrochemical studies on this residue in powder form have not yet been identified. Cocoa bean shell is composed of pectin polysaccharides, hemicellulose, cellulose, and Klason lignin which are a protein-Maillard-tannin complex ${ }^{22}$. Furthermore, the amount and profile of phenolic compounds present in this residue are very significant, so this class of compounds may show antioxidant properties ${ }^{20}$.

Thus, in the present work, the potentiality of the cocoa bean shell in its powder form as a corrosion inhibitor for SAE 1008 carbon steel in acidic medium $\left(\mathrm{HCl} 0.5 \mathrm{~mol} \mathrm{~L}^{-1}\right)$ was evaluated using electrochemical techniques (polarization curves, EIS, scanning vibrating electrode technique) and weight loss measurements. The adsorption isotherms were also studied to understand the type of interaction between the molecules present in the inhibitor (adsorbate) and the metallic substrate. Additionally, the economic comparison between the studied corrosion inhibitor and commercial inhibitors was realized.

\section{Materials and Methods}

\subsection{Corrosion inhibitor synthesis}

The cocoa shells were supplied by Fazenda Riachuelo - Mendoá Chocolates (Rodovia Ilhéus-Uruçuca (BahiaBrazil)). This material was treated in an oven $(1000 \mathrm{~W})$ at a temperature of $70^{\circ} \mathrm{C}$ for 6 hours. Afterward, the cocoa shells were ground in a ball mill Marconi model MA 500 (50 W) for 1 hour, containing 240 balls of ceramic material. Then, the fragmented material was taken to a Tyler sieve system $(450 \mathrm{~W})$ for 15 minutes, to obtain the powder with a particle size greater than 170 mesh.

\subsection{Steel samples preparation}

The metallic material used was SAE 1008 carbon steel, with the following composition (wt \%): C: 0.03; Si: 0.01; Mn: 0.20; P: 0.024; S: 0.013; Al: 0.031; Nb: 0.001; V: 0.001; Ti: 0.001; Cr: 0.01; Ni: 0.01; Sn: 0.001; N: 0.0028; B: 0.0027; Sb: 0.001 , and Fe: balance. For the tests carried out, the samples of carbon steel were cut in dimensions of $20 \mathrm{~mm} \times$

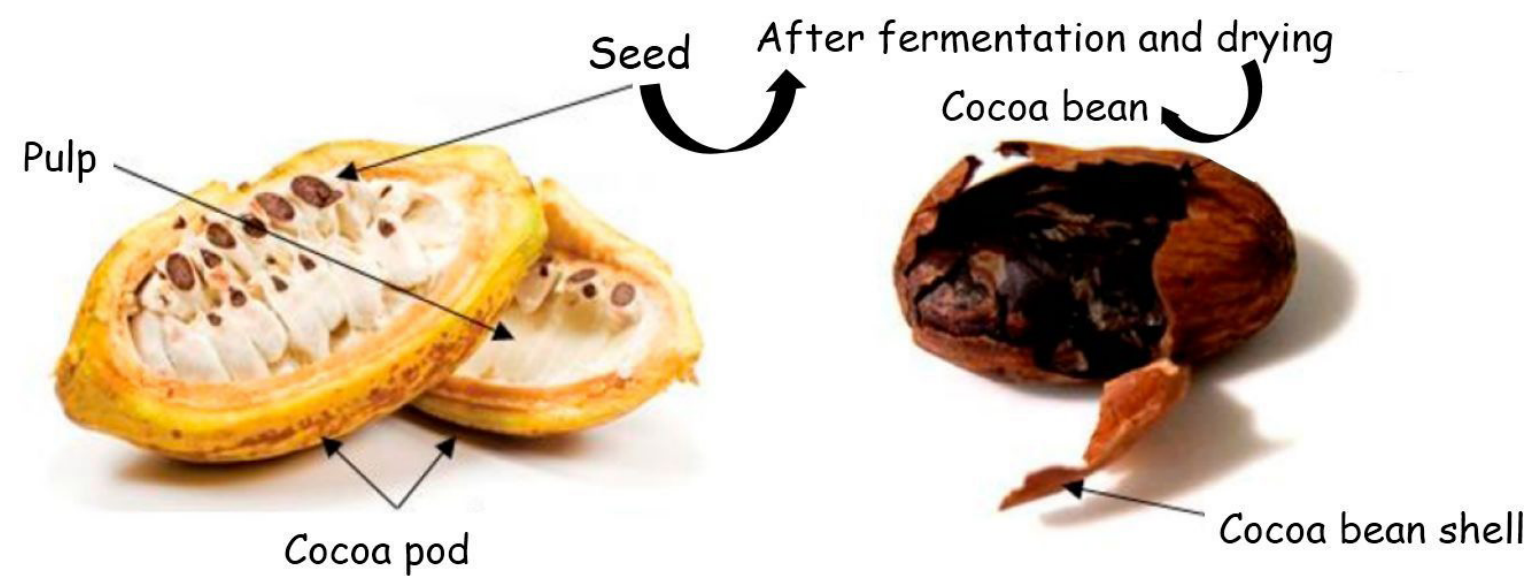

Figure 1. The fruit of cocoa and the cocoa shell. Adapted from Rojo-Poveda et al. (2020). 
$20 \mathrm{~mm} \times 1 \mathrm{~mm}$, and their surfaces were mechanically treated with $80,120,320,400,600,1200,2000$, and 2500 grit emery paper. Then, the samples were washed with distilled water to remove residues from the emery paper and then washed with ethanol, and acetone. Finally, the metal surface was dried with a hot air stream.

\subsection{Electrochemical tests}

The electrochemical tests were carried out in a threeelectrode system in an electrochemical cell, where the SAE 1008 carbon steel was employed as the working electrode (with an exposed area of $1.0 \mathrm{~cm}^{2}$ ), the $\mathrm{Ag}|\mathrm{AgCl}| \mathrm{KCl}$ sat as reference electrode and a titanium wire coated with rhodium as the counter electrode. The electrolyte was a $0.5 \mathrm{~mol} \mathrm{~L}^{-1} \mathrm{HCl}$ solution naturally aerated at $25^{\circ} \mathrm{C}$.

The electrochemical tests were carried out in a Metrohm Autolab potentiostat/galvanostat; model PGSTAT302N with NOVA 1.11 software. Microcal Origin 8.0 software was used to process the data. Five different concentrations of cocoa bean shell powder (CBSP) were added in the electrolyte in this study: $0.44 \mathrm{gL}^{-1}, 0.77 \mathrm{gL}^{-1}, 1.11 \mathrm{gL}^{-1}, 1.44 \mathrm{gL}^{-1}$, and $1.77 \mathrm{~g} \mathrm{~L}^{-1}$. The volume of acid solution used in all tests (electrochemical and gravimetric) was equal to $90 \mathrm{ml}$. As the CBSP was not completely soluble in $\mathrm{HCl}$, after adding the inhibitor mass to the electrolyte, the solution was stirred for 15 minutes on a Fisatom magnetic stirrer. After stirring, the samples were subjected to electrochemical tests.

Initially, the open circuit potential (OCP) measurements were carried out for 90 minutes to stabilize the corrosion potential. Then, electrochemical impedance spectroscopy (EIS) measurements were performed, using a frequency range of $100 \mathrm{kHz}$ to $10 \mathrm{mHz}$ with 10 points per decade and amplitude of $10 \mathrm{mV}(\mathrm{rms})$. For quantitative analyzes, EIS data were fitted with Zview software.

Subsequently to the EIS measurements, the polarization curves were performed. The anodic curves were performed at potential values of $-30 \mathrm{mV}$ to $+250 \mathrm{mV}$ versus $\mathrm{OCP}$, and cathodic curves at potentials of $-250 \mathrm{mV}$ to $+30 \mathrm{mV}$ versus OCP, both with a scanning rate of $0.5 \mathrm{mV} \mathrm{s}^{-1}$.

\subsection{Scanning vibrating electrode technique (SVET)}

The equipment used was the Applicable Electronics, controlled by software ASET-Science Wares. The distance between the sample surface and the vibrating probe was $100 \mu \mathrm{m}$. The SVET maps were obtained in 5, 30, and 90 minutes after immersion of the carbon steel in the electrolyte $(\mathrm{HCl}$ $\left.0.001 \mathrm{~mol} \mathrm{~L}^{-1}\right)$. These assays were conducted in the presence and absence of the corrosion inhibitor.

\subsection{Gravimetric tests}

The carbon steel samples were sanded, washed, and dried with hot air, as previously described. Then, the weights of the steel plates were measured using an analytical balance with a precision of $0.1 \mathrm{mg}$ (of the brand Marte Científica model AY220). Subsequently, they were immersed in the aqueous solution of $0.5 \mathrm{~mol} \mathrm{~L}^{-1} \mathrm{HCl}$, in the absence and presence of different inhibitor concentrations for 2 hours (in the first 15 minutes, the electrolyte-inhibitor mixture was stirred). After the immersion time, the samples were washed and cleaned with the aid of a brush. Then they were dried with hot air to measure their weight loss values. The weight loss tests were carried out according to the ASTM G1-03 standard ${ }^{23}$.

\subsection{Chemical characterization of the inhibitor}

For the characterization of functional groups present in the CBSP, Fourier Transform Infrared Spectroscopy (FTIR) were performed using a spectrophotometer from Thermo Scientific Nicolet, model iS10 by ATR (Attenuated Total Reflectance), in the range of 4000 to $650 \mathrm{~cm}^{-1}$, at a resolution of $4 \mathrm{~cm}^{-1}$ and 64 accumulated spectra.

\subsection{Scanning electron microscopy (SEM)}

To analyze the surface morphology of carbon steel, in the presence and absence of inhibitor, the Scanning Electron Microscopy was used. SEM images were obtained by Quanta 250F microscope after weight loss measurements.

\subsection{Economic evaluation}

The direct cost of production on a laboratory scale, of $1000 \mathrm{~g}$ of the studied corrosion inhibitor was evaluated. Thus, it was considered the transport costs of the residue removal at the cocoa factory and the energy costs of the process - milling, drying, and sieving. The cost per kilowatthour considered was $\$ 0.12$.

As the production costs of commercial inhibitors were not available, the average commercial value of these compounds was obtained from three suppliers. Table 2 shows these values. Besides, the objective of this work is to motivate the readjustment of an active industry of corrosion inhibitors. Thus, the necessary costs to start a new corrosion inhibitor factory were not evaluated.

\section{Results and Discussion}

\subsection{Chemical characterization of the inhibitor}

The chemical characterization was analyzed by Fourier Transform Infrared Spectroscopy (FTIR). Figure 2 and Table 3 present the bands and functional groups identified in this inhibitor.

The spectrum of Figure 2 shows an absorption band at $3270 \mathrm{~cm}^{-1}$, which can be attributed to the axial deformation of $\mathrm{O}-\mathrm{H}$ or the $\mathrm{N}-\mathrm{H}$ group. The $\mathrm{OH}$ group can be associated with the phenolic compounds and fatty acids present in the cocoa shell ${ }^{24}$. The N-H bonds can be derived from the theobromine and caffeine of the cacao residue ${ }^{20}$.

The absorption band at $1734 \mathrm{~cm}^{-1}$ can be attributed to the $\mathrm{C}=\mathrm{O}$ bonds present in the aromatic rings of lignin and the saturated fatty acids present in the CBSP. The presence of bands in the regions at $1033 \mathrm{~cm}^{-1}$ and $1176 \mathrm{~cm}^{-1}$, can be attributed to the $\mathrm{C}-\mathrm{O}$ or $\mathrm{C}-\mathrm{N}$ group $^{22,25}$.

Table 2. The average price of commercial corrosion inhibitors.

\begin{tabular}{cc}
\hline Compound & Average price $\left(U S D \mathrm{~kg}^{-1}\right)$ \\
\hline Pyrazolone & $150 \pm 34$ \\
\hline Benzethonium chloride & $333 \pm 44$ \\
\hline Benzotriazole & $195 \pm 46$ \\
\hline Benzothiazole & $192 \pm 44$ \\
\hline Dibenzylthiourea & $1930 \pm 150$ \\
\hline
\end{tabular}


The band at $1610 \mathrm{~cm}^{-1}$ can be attributed to the stretching of the $\mathrm{C}=\mathrm{C}$ bonds, associated with the presence of lignin and also aromatic compounds from flavonoids of the CBSP ${ }^{19,26}$.

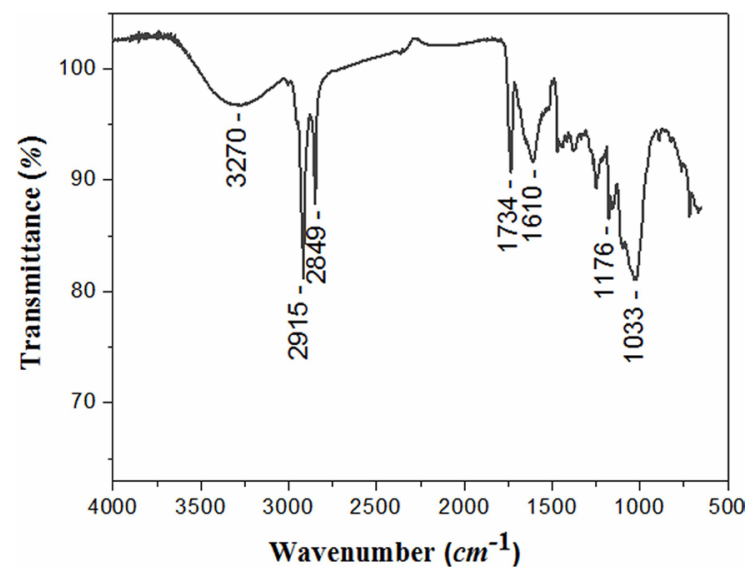

Figure 2. FTIR spectrum of the cocoa bean shell powder.

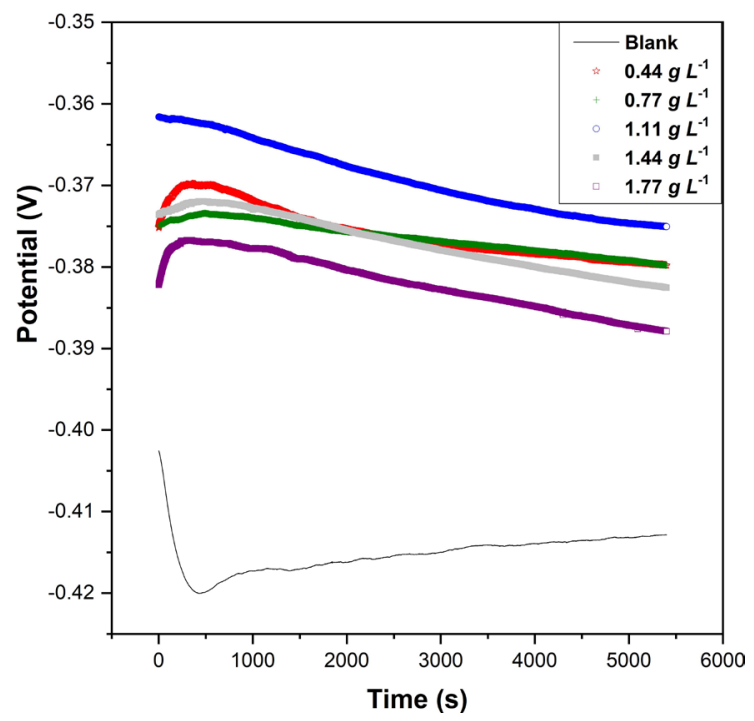

Figure 3. OCP plots for carbon steel in the absence and presence of different concentrations of the cocoa bean shell powder.
Thus, functional groups with oxygen, nitrogen, and double bonds ( $\mathrm{C}-\mathrm{O}, \mathrm{O}-\mathrm{H}, \mathrm{N}-\mathrm{H}, \mathrm{C}-\mathrm{N}, \mathrm{C}=\mathrm{O}$, and $\mathrm{C}=\mathrm{C}$ ) were observed in the spectrum of cocoa shell powder. According to Rocha et al. (2014), the presence of organic compounds containing nitrogen, oxygen, sulfur, and double or triple bonds facilitates their adsorption on metal surfaces and thus blocking their active areas ${ }^{11}$.

\subsection{Electrochemical impedance spectroscopy (EIS)}

The electrochemical impedance tests were performed after 90 minutes of Open Circuit Potential (OCP) monitoring. Figure 3 shows the monitoring of the during this period.

Figure 3 shows that the time of 5400 seconds was sufficient for the stabilization of the OCP in the corrosion potential, demonstrating the equilibrium of the reactions at the electrode/solution interface. After obtaining the steady state OCP, impedance measurements were performed. Figure 4 shows the Nyquist and Bode diagrams obtained for SAE 1008 carbon steel in $0.5 \mathrm{~mol} \mathrm{~L}^{-1} \mathrm{HCl}$ solutions in the absence and presence of different inhibitor concentrations.

The Nyquist plot (Figure 4 (a)) for the blank sample presents only one depressed capacitive loop, showing that the corrosion kinetics is controlled by the charger transfer resistance. In the corrosion inhibitor presence, the shape of the plots remains the same, which demonstrates that the electrochemical behavior is not affected by the presence of the inhibitor. Nevertheless, an increase in the diameter of the semicircles occurs for increasing inhibitor concentration, denoting the reduction of the corrosion rate.

Similarly to Nyquist diagrams, Bode diagrams (Figure 4 (b) and (c)) do not show any change in the shape of the plots, which demonstrates that the corrosion mechanism remains the same ${ }^{27}$. Furthermore, there is only a single and

Table 3. FTIR functional groups identified in the inhibitor spectra ${ }^{22,24,41}$

\begin{tabular}{cc}
\hline Bands Wavenumber $\left(\mathrm{cm}^{-1}\right)$ & Functional Group attribution \\
\hline $3600-3200$ & O-H \\
\hline $3500-3100$ & N-H \\
\hline $3000-2850$ & C-H alkanes (stretching) \\
\hline $2900-2800$ & C-H (aldehyde) \\
\hline
\end{tabular}
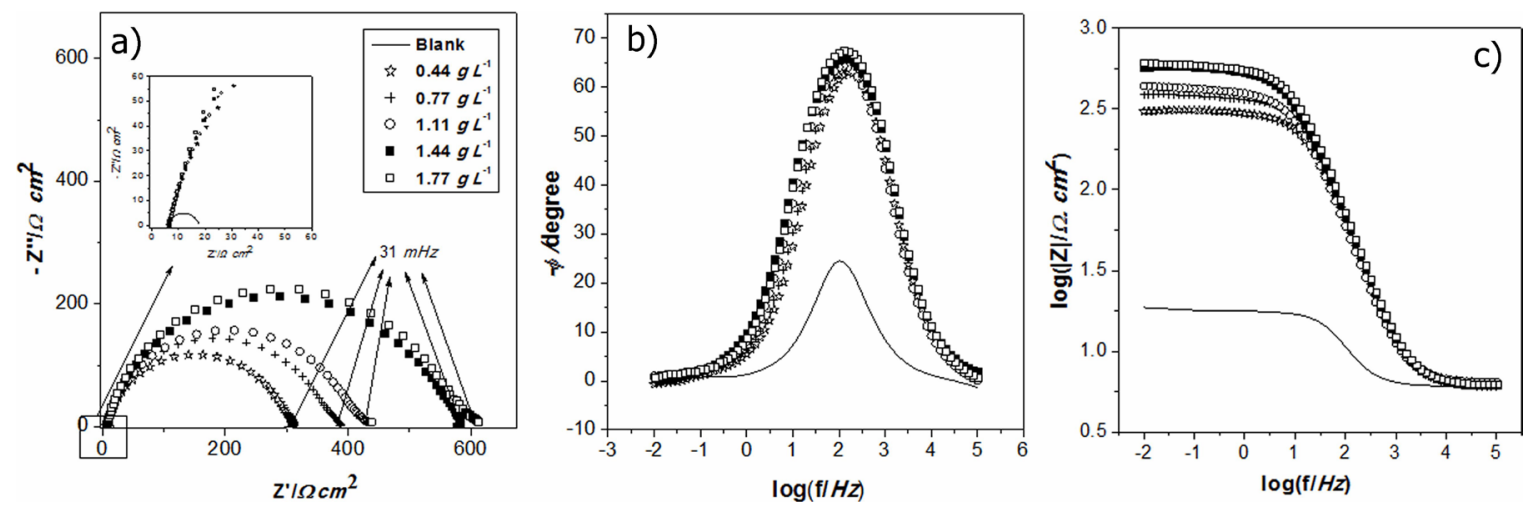

Figure 4. Nyquist (a) and Bode plots, for phase angle (b) and the logarithm of the impedance modulus (c) for carbon steel in the absence and presence of different concentrations of the cocoa bean shell powder in the $0.5 \mathrm{~mol} \mathrm{~L}^{-1} \mathrm{HCl}$ solution. 
narrow peak in the phase angle plots in Figure 4 (b), indicating that there is a single time constant related to the electrical double layer formation at the metal-solution interface ${ }^{28}$.

The electrochemical impedance diagrams obtained were analyzed through another approach, which correlates the impedance data with an electrical equivalent circuit, represented in Figure 5. Using the Z-View software, the experimental data were fitted to the equivalent circuit model, which represents a parallel combination of the charge transfer resistance $\left(R_{\mathrm{ct}}\right)$ and the electrical double layer capacitance considering the introduction of the constant phase element $\left(C P E_{\mathrm{d} 1}\right)$, both in series with the resistance of the solution $\left(R_{\mathrm{s}}\right)$. This equivalent circuit is in agreement with what is found in the literature ${ }^{12,16,27-30}$.

The corrosion inhibitor efficiency $\left(\eta_{\mathrm{wL}}\right)$, as presented in Equation 1, can be calculated using the charge transfer resistance ${ }^{29}$.

$\eta_{\mathrm{WL}}=\frac{R_{\mathrm{ct}}-R_{\mathrm{ct}, 0}}{R_{\mathrm{ct}}} .100$

Where $R_{\mathrm{ct}, 0}$ is the charge transfer resistance in the absence of inhibitor and $R_{\mathrm{ct}}$ represents the charge transfer resistance in the presence of the inhibitor ${ }^{29}$.

A constant phase element is introduced into the circuit instead of a pure capacitor to represent the electrical double layer, to compensate for the inhomogeneous surface and deviations from the ideal behavior, providing greater precision to the data fit. The impedance of a $C P E\left(Z_{\mathrm{CPE}}\right)$ is expressed mathematically according to Equation $2^{29-30}$.

$$
Z_{C P E}=Y_{0}^{-1}(j \omega)^{-\alpha}
$$

Where $Y_{0}$ is the $C P E$ value, $\omega$ is the angular frequency, $j^{2}$ is -1 , and $\alpha$ is the dispersion factor, it is related to the phase angle of the $C P E$ and according to the ideality of the system, which is between 0 and 1 . When this value is equal to 1 , it is a pure capacitor and the behavior is of an ideal electrode ${ }^{29,31}$. The data obtained through the fitting of EIS data to the equivalent circuit model are presented in

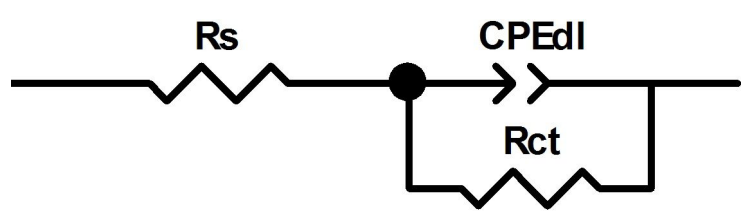

Figure 5. Electrical equivalent circuit used to fit the EIS data.
Table 4. The quality of the fitted data was expressed by the values of $\chi^{2}$ (chi-square).

The values of $\chi^{2}$ obtained are lower than $1.0010^{-3}\left(1.2510^{-4}\right.$ to $3.010^{-4}$ ), which is indicative of a good fit for the proposed circuit model $^{31}$. The values for the dispersion factor vary from 0.87 to 0.88 , with no significant differences occurring in the absence or presence of different concentrations of the inhibitor. Thus, these values are around 0.9 , which demonstrates proximity to pure capacitor behavior ${ }^{16}$.

Table 4 shows that the $\mathrm{CPE}_{\mathrm{dl}}$ values decreased. Yetri et al. (2018) observed a behavior similar to this when they evaluated the anticorrosive activity of a cocoa residue. They studied the cacao peel extract and suggested that the decrease of capacitance with the increase of extract concentration was related to the reduction in the local dielectric constant and/or the increase in the thickness of the double layer formed due to adsorption of molecules on the metal surface ${ }^{14}$. Thus, it is suggested that similar behavior occurs when the antioxidant molecules present in the CBSP are adsorbed on the surface of the carbon steel ${ }^{12,14}$.

Table 4 also shows that increasing inhibitor concentration increases $R_{\mathrm{ct}}$ values. This behavior is due to the increase in the surface coverage caused by the inhibitory molecules, indicating that the exposed area to the corrosive medium has decreased ${ }^{32}$. The highest $R_{\mathrm{ct}}$ value was verified for the highest concentration of inhibitor employed, whose value is $1.77 \mathrm{~g} \mathrm{~L}^{-1}$. For this same concentration, it was also found to be the highest efficiency value in the corrosion inhibition. Besides, for lower concentrations of the inhibitor, the inhibition efficiency is higher than $70 \%$, which is considered by the classic literature ${ }^{33}$ as the minimum efficiency value for an effective inhibition against corrosion. When compared to commercial inhibitors (Table 2), the studied inhibitor needs a higher concentration to achieve the same efficiency.

\subsection{Potentiodynamic polarization curves}

The potentiodynamic polarization curves were obtained after the EIS experiments. Thus, these curves were obtained after 105 minutes of immersion in the electrolyte. The Tafel plot is presented in Figure 6.

Using the Tafel extrapolation method, the parameters shown in Table 5 were obtained: corrosion potential $\left(\mathrm{E}_{\text {corr }}\right)$, corrosion current density $\left(\mathrm{I}_{\text {corr }}\right)$ and the anodic $\left(\mathrm{b}_{\mathrm{a}}\right)$ and cathodic $\left(b_{c}\right)$ Tafel constants. From the $I_{\text {corr }}$ values obtained, the corrosion inhibition efficiency ( $\mathrm{IE}_{\mathrm{Icorr}}$ ) was calculated, according to the Equation $3^{29-30}$ :

Table 4. Electrochemical parameters obtained through the system electrical equivalent circuit in $0.5 \mathrm{~mol} \mathrm{~L}^{-1} \mathrm{HCl}$.

\begin{tabular}{ccccccc}
\hline $\begin{array}{c}\text { Inhibitor } \\
\text { Concentration } \\
\left(g L^{-1}\right)\end{array}$ & $R_{\mathrm{s}}\left(\Omega \mathrm{cm}^{2}\right)$ & $R_{\mathrm{ct}}\left(\Omega \mathrm{cm}^{2}\right)$ & $\begin{array}{c}C P E_{\mathrm{dl}} \\
\left(F \mathrm{~cm}^{-2} \mathrm{~s}^{(\alpha-1)}\right)\end{array}$ & $\alpha$ & $\chi^{2}$ & $\begin{array}{c}\text { Inhibition } \\
\text { Efficiency }(\%)\end{array}$ \\
\hline Blank & 6.09 & 11.6 & $4.79 \times 10^{-4}$ & 0.88 & $1.25 \times 10^{-4}$ & - \\
\hline 0.44 & 6.36 & 293.0 & $5.72 \times 10^{-5}$ & 0.87 & $1.76 \times 10^{-4}$ & 96.03 \\
\hline 0.77 & 5.95 & 356.9 & $5.22 \times 10^{-5}$ & 0.87 & $3.01 \times 10^{-4}$ & 96.74 \\
\hline 1.11 & 6.14 & 454.4 & $5.44 \times 10^{-5}$ & 0.87 & $1.84 \times 10^{-4}$ & 97.44 \\
\hline 1.44 & 6.14 & 485.6 & $5.06 \times 10^{-5}$ & 0.87 & $1.65 \times 10^{-4}$ & 97.60 \\
\hline 1.77 & 6.20 & 559.4 & $5.04 \times 10^{-5}$ & 0.87 & $2.42 \times 10^{-4}$ & 97.92 \\
\hline
\end{tabular}




$$
I E_{\text {Icorr }}(\%)=\frac{I_{\text {corr }}^{0}-I_{\text {corr }}}{I_{\text {corr }}^{0}} .100
$$

Where: $\mathrm{I}^{0}$ irr is the corrosion current density without inhibitor and $\mathrm{I}_{\text {corr }}$ is the corrosion current density in the presence of the inhibitor ${ }^{29-30}$.

Figure 6 shows that current densities - anodic and cathodic - decreased in the presence of the inhibitor. Table 5 shows that, in the presence of the CBSP, the corrosion potentials were slightly shifted to more positive values when compared to blank. But those values did not change significantly with respect to the inhibitor concentrations, therefore, the CBSP can be classified as mixed type inhibitor ${ }^{28-29}$. Other natural corrosion inhibitors reported in the literature have also been considered within this classification ${ }^{11,14,16,27-31}$.

There was a reduction in the anodic and cathodic Tafel constants, thus, this behavior suggests that the adsorbed species of the CBSP altered both the mechanism of the metal dissolution reaction (anodic) and the hydrogen evolution reaction (cathodic) $)^{30-31}$.

The $\mathrm{IE}_{\text {Icorr }}$ data increased with increasing CBSP concentration, demonstrating that the adsorption of inhibitory molecules on the metallic substrate can minimize the transfer of electrons at the metal-solution interface, decreasing the corrosive process ${ }^{14}$. The corrosion inhibition efficiency values calculated through the polarization curves corroborate the efficiency data obtained by the EIS technique. Despite

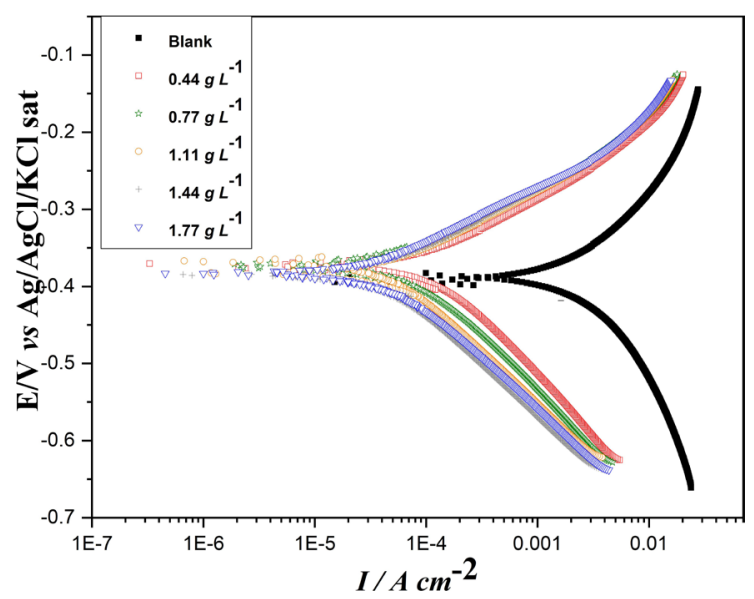

Figure 6. Tafel plot for SAE 1008 carbon steel in $0.5 \mathrm{~mol} \mathrm{~L}^{-1} \mathrm{HCl}$ solution in the absence and presence of different concentrations of cocoa bean shell powder. coming from different techniques, the differences between the efficiency values of both techniques were less than $3 \%$.

\subsection{Scanning vibrating electrode technique (SVET)}

The SVET technique helped verify areas of occurrence of corrosion, evidencing the anodic and cathodic zones, both in the absence of inhibitor and in the presence of $1.77 \mathrm{gL}^{-1}$ of the cocoa bean shell powder. This concentration of inhibitor was chosen because it results in the highest inhibition efficiency from other electrochemical techniques.

Figure 7 shows the ionic currents maps of the carbon steel surface immersed in $0.001 \mathrm{~mol} \mathrm{~L}^{-1} \mathrm{HCl}$ solution without inhibitor. By these maps, the aggressiveness of the medium is evident, due to the several regions with anodic ionic currents (the region in yellow and red colors) with high intensity, resulting from the oxidation process of the iron present in the steel, and also extensive regions where densities of cathodic ionic currents (blue color region) were detected, resulting from the hydrogen reduction process ${ }^{34}$.

The tendency to a localized corrosive attack on the sample can be noted by the concentration of intense anodic ionic currents in small area locations on the exposed surface. In contrast, the cathodic ionic currents have lower-intensity but are present in a larger area of the sample. As the immersion time increases, the anodic and cathodic regions become well defined and more intense.

In the presence of the inhibitor, in the first minutes of immersion, there is a low intensity of the anodic currents, which can be verified by the ionic current densities in Figure 8. Using $1.77 \mathrm{~g} \mathrm{~L}^{-1}$ of CBSP, there is a notable decrease in the anodic ionic currents. Thus, through the SVET maps, the performance of cocoa bean shell powder as a corrosion inhibitor for SAE 1008 carbon steel in acidic medium was verified, which corroborates the results obtained by other electrochemical techniques.

\subsection{Gravimetric tests}

Corrosion rate $\left(C_{\mathrm{R}}\right)$, corrosion current density $\left(i_{\text {corr }}\right)$, degree of surface coverage $(\theta)$, and inhibition efficiency $(\eta)$ were obtained through the gravimetric tests.

The corrosion rate can be calculated by the weight loss in grams $(\Delta \mathrm{W})$, the total exposed area to the electrolytic solution $(s)$, and the immersion time $(t)$, according to Equation $4^{31}$ :

$$
C_{\mathrm{R}}=\frac{\Delta W}{s . t}
$$

The inhibition efficiency $(\eta)$, in percentage $(\%)$, was calculated according to Equation 5. From this parameter,

Table 5. Polarization parameters for carbon steel in $0.5 \mathrm{~mol} \mathrm{~L}^{-1} \mathrm{HCl}$ solution in the absence and presence of different concentrations of cocoa bean shell powder.

\begin{tabular}{cccccc}
\hline Inhibitor concentration $\left(\mathrm{g} \mathrm{L}^{-1}\right)$ & $\mathrm{E}_{\text {corr }}(\mathrm{mV})$ & $\mathrm{I}_{\text {corr }}\left(\mu \mathrm{Acm} \mathrm{cm}^{-2}\right)$ & $\mathrm{b}_{\mathrm{a}}\left(\mathrm{mV} \mathrm{dec}{ }^{-1}\right)$ & $-\mathrm{b}_{\mathrm{c}}\left(\mathrm{mV} \mathrm{dec}^{-1}\right)$ & $\mathrm{IE}_{\text {Icorr }}(\%)$ \\
\hline Blank & -389 & 1989 & 166 & 258 & - \\
\hline 0.44 & -374 & 103 & 75 & 138 & 94.83 \\
\hline 0.77 & -376 & 61 & 73 & 127 & 96.92 \\
\hline 1.11 & -380 & 52 & 75 & 129 & 97.39 \\
\hline 1.44 & -387 & 39 & 74 & 122 & 98.03 \\
\hline 1.77 & -383 & 35 & 72 & 118 & 98.22 \\
\hline
\end{tabular}



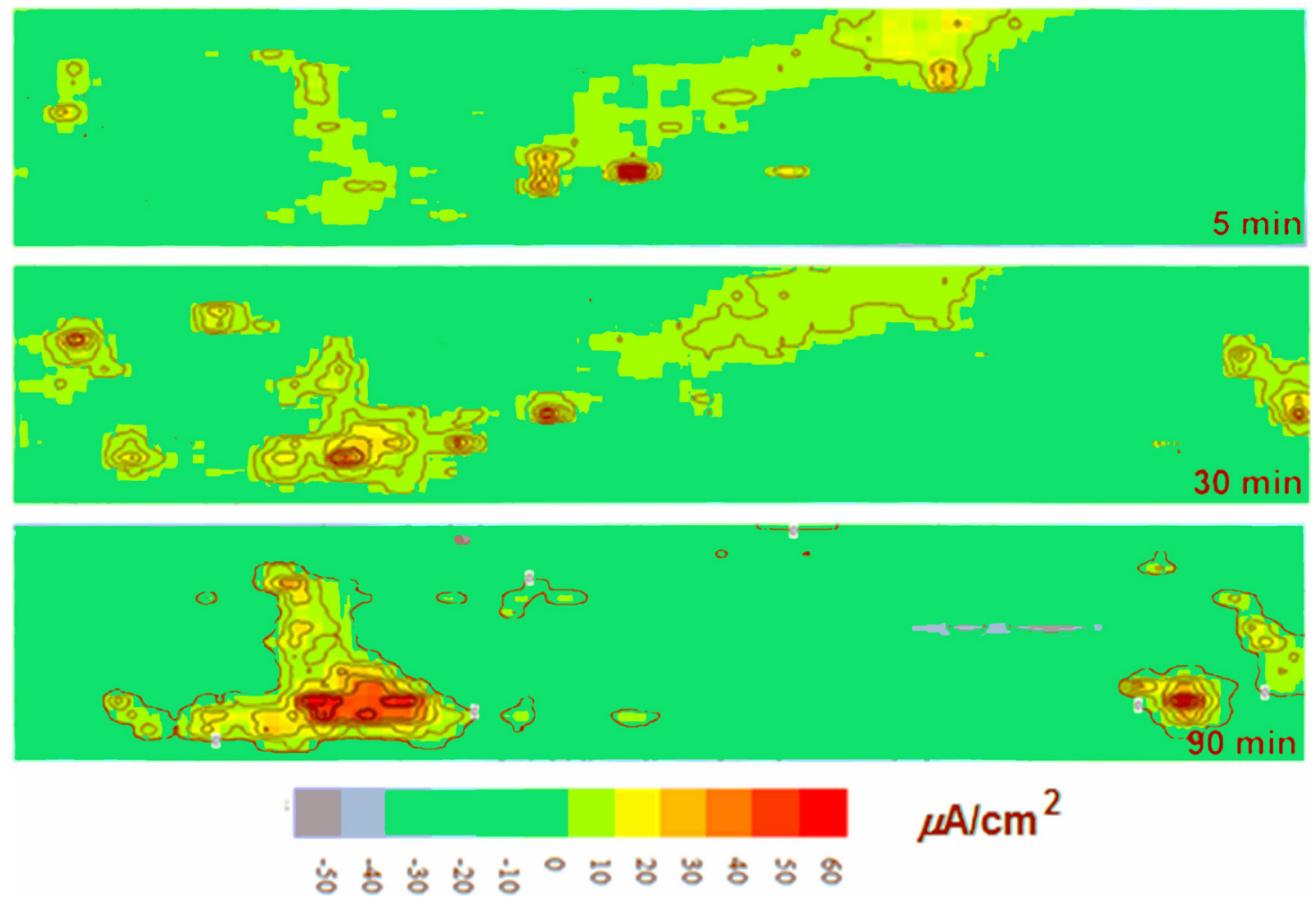

\section{$\mu \mathrm{A} / \mathrm{cm}^{2}$}

Figure 7. SVET ionic currents maps obtained for SAE 1008 carbon steel after 5, 30 and 90 minutes of immersion in $0.001 \mathrm{~mol} \mathrm{~L}^{-1} \mathrm{HCl}$ solution.
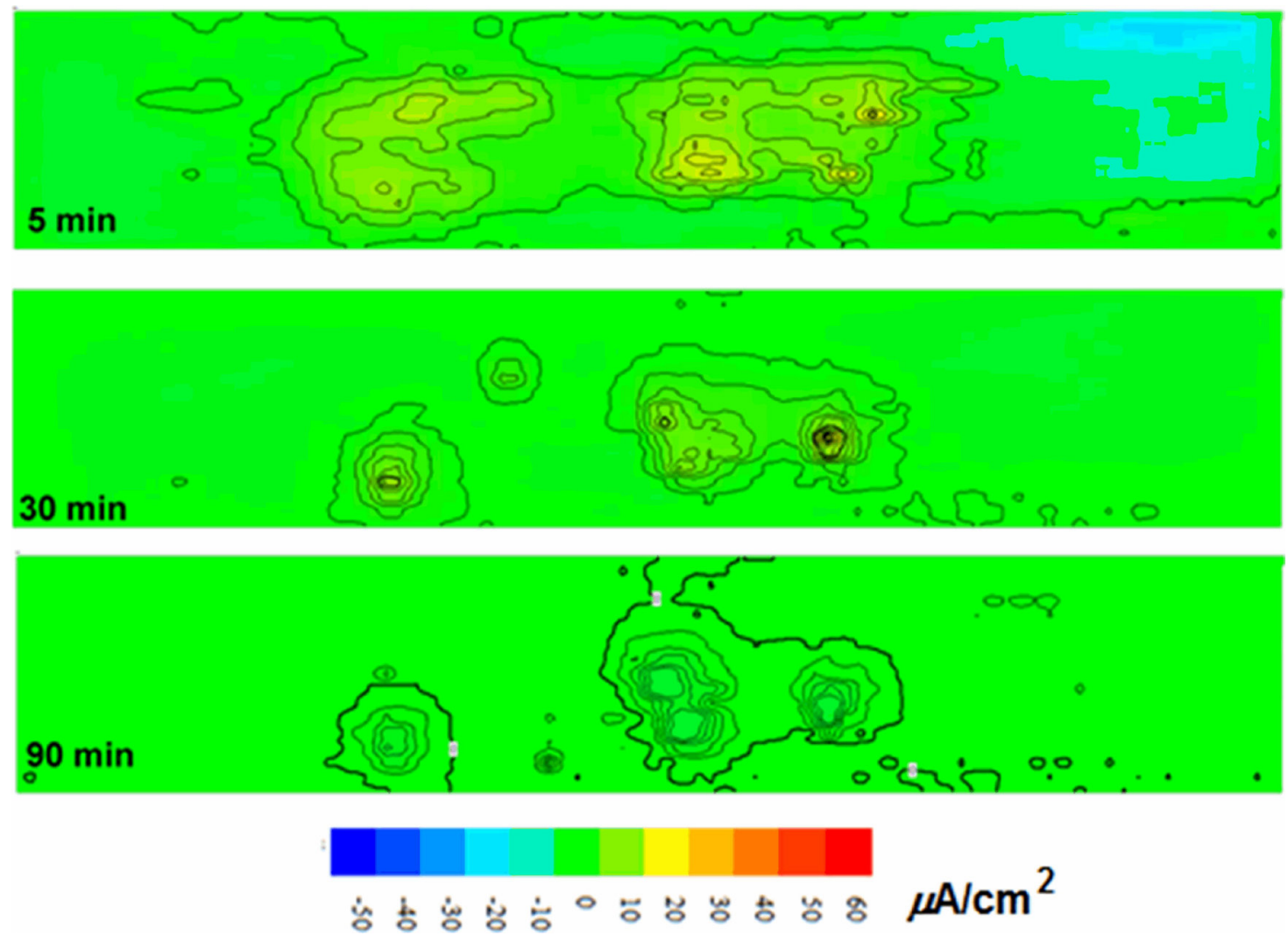

Figure 8. SVET ionic current maps obtained for SAE 1008 carbon steel after 5, 30 and 90 minutes of immersion in $0.0010 .5 \mathrm{~mol} \mathrm{~L} \mathrm{~L}^{-1} \mathrm{HCl}$ solution in the presence of $1.77 \mathrm{gL}^{-1}$ inhibitor. 
the degree of coverage of the metal surface $(\theta=\eta / 100)$ is also calculated ${ }^{29,31}$.

$\eta=\frac{C_{\mathrm{R}}^{0}-C_{\mathrm{R}}}{C_{\mathrm{R}}^{0}} .100$

Where $C_{\mathrm{R}}{ }^{0}$ is the corrosion rate in the absence of the inhibitor and $C_{\mathrm{R}}$ is the corrosion rate in the presence of the inhibitor ${ }^{31}$.

Corrosion current density $\left(i_{\text {corr }}\right)$ was also calculated by Equation $6^{15}$ :

$i_{\text {corr }}=\mathrm{C}_{\mathrm{R}} \frac{96,500}{E_{\text {eqmetal }}}$

Where 96,500 $\mathrm{C} \mathrm{mol}^{-1}$ represents the value of the Faraday constant and $E_{\text {eqmetal }}$ is the equivalent-gram of the metal used. In this study, the electrode is carbon steel, whose $E_{\text {eqmetal }}$ value was $27.93 \mathrm{~g}$, corresponding to pure iron ${ }^{12,15}$.

Table 6 shows that by increasing the concentration of cocoa bean shell powder, corrosion rates and current densities decreased, while corrosion inhibition efficiency increased. Furthermore, the degree of surface coverage increased, indicating that the extent of adsorption on the steel surface increases with the increasing inhibitor concentration ${ }^{31}$.

Even at the lowest evaluated concentration $\left(0.44 \mathrm{~g} \mathrm{~L}^{-1}\right)$, the value of $\theta$ is close to unit $(\theta=0.93)$, suggesting that there is practically a total coverage of the steel surface with the adsorbed inhibitor molecules, thus forming a barrier that protects the metal surface ${ }^{28}$. This behavior reflects the inhibitory effect of the cocoa residue on the corrosion of carbon steel in acidic medium, which corroborates the Tafel extrapolation and EIS results obtained.

Even at the $0.5 \mathrm{~mol} \mathrm{~L}^{-1} \mathrm{HCl}$ concentration, the acidic medium is very aggressive for SAE 1008 carbon steel, which is a low carbon steel and it has low corrosion resistance. Thus, with the present research, the CBSP proved to be an efficient inhibitor. Thus, this study contributes positively to the search for new green corrosion inhibitors, with possible applications in cooling-water systems and in oil extraction pipelines.

\subsection{Adsorption isotherm}

The values of the degree of coverage of the metal surface $(\theta)$ and inhibitor concentration $(C)$ were fitted in different models of adsorption isotherms; to clarify the interactions between the adsorbate and the substrate. The models tested were: Langmuir, Freundlich, Temkin, Frumkin, and El-Awady, according to the following equations ${ }^{1,35-37}$ :

Langmuir isotherm: $\frac{C}{\theta}=\frac{1}{K}+C$

Freundlich isotherm $: \log \theta=\log K_{f}+1 / n \log C$

Temkin isotherm $: \theta=\left(-\frac{2.303}{2 a}\right) \log \mathrm{K}+\left(-\frac{2.303}{2 a}\right) \log \mathrm{C}$

Frumkin isotherm $: \log (\theta /(1-\theta) . \mathrm{C})=\log \mathrm{K}+\mathrm{g} \theta$

El-Awady isotherm $: \log \left(\frac{\theta}{1-\theta}\right)=\log \mathrm{K}+\mathrm{y} \log \mathrm{C}$

Where: $\mathrm{K}$ is the adsorption constant, $\mathrm{n}$ is an adsorption heterogeneity parameter, $\mathrm{K}_{\mathrm{f}}$ is the Freundlich constant, $a$ is the lateral interaction parameter among the adsorbed molecules, $g$ is the interaction parameter of the adsorbate and $y$ represents the number of molecules of the inhibitor that occupy a given active site ${ }^{1,35-38}$.

The adsorption parameters obtained for each isotherm and the correlation coefficients $\left(\mathrm{R}^{2}\right)$ of the equations of a straight line are shown in Table 7.

The Freundlich isotherm assumes that the slope of the equation is a heterogeneity parameter $(1 / \mathrm{n})$, so the smaller it is $1 / \mathrm{n}$, the greater the heterogeneity of the system. For the experimental data evaluated, the slope is equal to 0.0334 , as shown in Table 7. This suggests a great heterogeneity in the studied system ${ }^{35}$.

The Temkin isotherm considers that the heat of adsorption of the molecules decreases linearly with the degree of coverage of the metal surface due to interactions between the adsorbed species. Thus, when the side interaction parameter for the

Table 6. Results from gravimetric tests in $0.5 \mathrm{~mol} \mathrm{~L}^{-1} \mathrm{HCl}$ solution.

\begin{tabular}{ccccc}
\hline Inhibitor concentration $\left(\mathrm{g} \mathrm{L}^{-1}\right)$ & $\mathrm{C}_{\mathrm{R}}\left(\mathrm{g} \mathrm{cm}^{-2} \mathrm{~h}^{-1}\right)$ & $\mathrm{i}_{\text {corr }}\left(\mathrm{A} \mathrm{cm}^{-2}\right)$ & $\Theta$ & - \\
\hline Blank & $2.24 \times 10^{-3}$ & $2.15 \times 10^{-3}$ & - & $\eta(\%)$ \\
\hline 0.44 & $1.55 \times 10^{-4}$ & $1.49 \times 10^{-4}$ & 0.930 & 93.05 \\
\hline 0.77 & $1.14 \times 10^{-4}$ & $1.10 \times 10^{-4}$ & 0.949 & 94.92 \\
\hline 1.11 & $1.05 \times 10^{-4}$ & $1.01 \times 10^{-4}$ & 0.953 & 95.31 \\
\hline 1.44 & $6.73 \times 10^{-5}$ & $6.46 \times 10^{-5}$ & 0.969 & 96.99 \\
\hline 1.77 & $5.95 \times 10^{-5}$ & $5.71 \times 10^{-5}$ & 0.973 & 97.34 \\
\hline
\end{tabular}

Table 7. Parameters obtained for different adsorption isotherms.

\begin{tabular}{ccc}
\hline Adsorption Isotherms & $\mathrm{R}^{2}$ & Equations of a straight line \\
\hline Langmuir $(\mathrm{C} / \theta$ versus $\mathrm{C})$ & 0.9999 & $\mathrm{y}=0.0329+1.0104 \mathrm{x}$ \\
\hline Freundlich $(\log \theta$ versus $\log \mathrm{C})$ & 0.9637 & $\mathrm{y}=-0.0198+0.0324 \mathrm{x}$ \\
\hline Temkin $(\theta$ versus $\log \mathrm{C})$ & 0.9626 & $\mathrm{y}=0.9555+0.0710 \mathrm{x}$ \\
\hline Frumkin $(\log (\theta /(1-\theta) / C)$ versus $\theta)$ & 0.4760 & $\mathrm{y}=4.5104-3.2989 \mathrm{x}$ \\
\hline El-Awady $(\log (\theta / 1-\theta))$ versus $\log \mathrm{C})$ & 0.7981 & $\mathrm{y}=1.0064 \mathrm{x}+1.4112$ \\
\hline
\end{tabular}


adsorbed molecules is negative $(a<0)$, it is considered that there is repulsion between them ${ }^{1,35}$. Thus, as the value of $a$ is negative, there is a repulsive interaction between the molecules of the of the cocoa bean shell powder on the surface of the carbon steel.

Frumkin's isotherm admits that the molecules interact with each other ${ }^{36}$. For this isotherm model, the worst correlation of the experimental data was obtained, as the correlation coefficient is not in the range between 0.60 and 0.99 , therefore, this fit is considered unsatisfactory ${ }^{37}$. In contrast, the best fit and greater linearity of the data were presented for Langmuir isotherm, whose coefficient of correlation was equal to 0.9999 . This can best be seen through the linear plot shown in Figure 9.

The Langmuir isotherm is based on the occurrence of inhibitor monolayer coverage on the steel surface, that is, each site adsorbs only one inhibitor molecule $\mathrm{e}^{30,37}$. Through Table 7, it is noted that the slope is very close to one unit (1.0104), reinforcing compliance with this isotherm model.

This information can be reaffirmed through El-Awady's kinetic-thermodynamic adsorption model, since the slope of this equation of a straight line also represents a close proximity to a unit (1.0064). According to El-Awady et al. (1992) the slope for this model represents the number of inhibitory molecules that occupy an active site on the metal surface $^{38}$. Thus, this parameter confirms that an active site is occupied by approximately only one molecule that inhibits the cocoa bean shell powder, corroborating the result observed in the Langmuir isotherm. Most of the studies reported in the literature on green corrosion inhibitors in acidic media reported that the Langmuir adsorption model was adequate to describe the adsorption process ${ }^{11,14,16,28-31}$.

From the equation of straight line for this better fit of the experimental data, using the graph $C / \theta$ as a function of $C$, we find the linear coefficient equal to $1 / K$. Through this adsorption constant, it is possible to calculate the Gibbs free energy of adsorption $\left(\Delta G_{\text {ads }}^{\mathrm{o}}\right)$, according to Equation $12^{36}$.

$\Delta G^{\mathrm{o}}$ ads $=-R T \ln \left(C_{H 2 O} K\right)$

Where $T$ is the absolute temperature (whose value in this present study is $298 K), R$ is the universal gas constant $\left(8.3147 \mathrm{~J} \mathrm{~mol}^{-1} \mathrm{~K}^{-1}\right), C_{\mathrm{H} 2 \mathrm{O}}$ is the water concentration and its value is $55.5 \mathrm{~mol} \mathrm{~L}^{-1}\left(1000 \mathrm{~g} \mathrm{~L}^{-1}\right)^{36}$.

The Gibbs adsorption free energy calculated for the present study is $-25.58 \mathrm{~kJ} \mathrm{~mol}^{-1}$. The negative signal indicates that the adsorption process of the inhibitor molecules on the metal surface occurs spontaneously. Besides the spontaneity, through this parameter, one can also evaluate if the phenomenon of physisorption or chemisorption occurs. Thus, when the values of $\Delta G_{\text {ads }}^{\mathrm{o}}$ are about $-40 \mathrm{~kJ} \mathrm{~mol}^{-1}$, they suggest the occurrence of the phenomenon of chemisorption, on the other hand, when the values of $\Delta G_{\text {ads }}^{\mathrm{o}}$ are around $-20 \mathrm{~kJ} \mathrm{~mol}^{-1}$ or less negative, the phenomenon of physisorption occurs ${ }^{29-30}$.

Thus, the inhibitory molecules present in the cocoa shell powder (that come from compounds that have functional groups with oxygen, nitrogen and double bonds) were physically adsorbed onto the carbon steel surface, which indicates that the adsorption forces involved are relatively weak and occurs through electrostatic interaction between the inhibitor ions and the electrically charged metal surface ${ }^{30,36}$. Through this interaction, the inhibitor forms a thin layer on the metal surface, helping to control the corrosion rate, promoting the separation between the steel and electrolyte ${ }^{14}$.

\subsection{SEM Characterization}

Figure 10 shows the surface of the sanded carbon steel before immersion in the acidic medium, exhibiting the scratches produced by the grinding process. Figure 11 (a) shows the surface aspect of the steel after immersion in the electrolyte in the absence of the inhibitor. In this condition a rugged and drastically damaged surface is observed, demonstrating the attack on the substrate caused by the aggressiveness of the acidic medium, which caused uniform corrosion on carbon steel $\mathrm{l}^{29,30,36}$

Figure 11 (b) shows the morphology of the metal surface, after immersion in the electrolyte, in the presence of $1.77 \mathrm{~g} \mathrm{~L}^{-1}$ of the inhibitor. Note some lines from the grinding and a surface less attacked than the one shown in Figure 11 (a). This improvement in the morphology of the metallic surface indicates the formation of an efficient protective film by adsorption of the molecules present in the cocoa bean shell powder ${ }^{12-16}$.

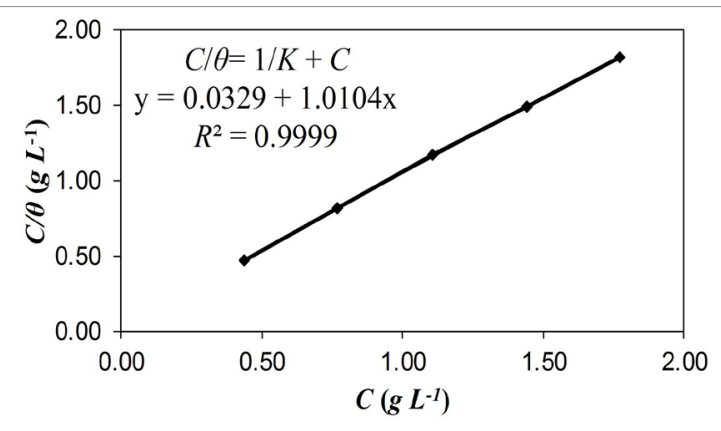

Figure 9. Langmuir adsorption isotherm for SAE 1008 carbon steel for different concentrations of cocoa bean shell powder in $0.5 \mathrm{~mol} \mathrm{~L}^{-1} \mathrm{HCl}$.

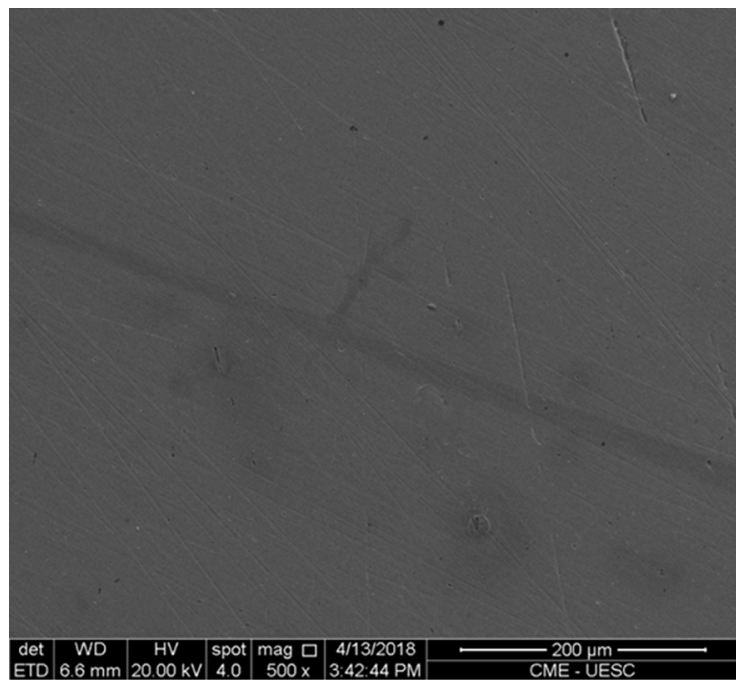

Figure 10. SEM Micrograph of the SAE 1008 carbon steel before immersion in the electrolyte. 


\subsection{Effect of immersion time on corrosion inhibition efficiency}

To evaluate the behavior of the CBSP in relation to the time of immersion in the acidic media, EIS tests were performed in the absence and presence of inhibitor at different immersion times $(2,6,12,24,48$, and $72 h)$. The inhibitor concentration of used for these tests was $1.77 \mathrm{~g} \mathrm{~L}^{-1}$, because in the other tests performed, this concentration demonstrated the best performance in terms of corrosion inhibition efficiency. Figure 12 shows the Nyquist and Bode plots in the different immersion times studied.

Figure 12 shows that in the initial evaluated times there is no significant difference in the values of phase angle (b) and logarithm of the impedance modulus (c). In 12 hours of immersion there is a slight increase in the diameter of the capacitive semicircle (a) and in the values of phase angle (b) and impedance module (c). This suggests that in the first 12 hours the corrosion process was stable, thus, the inhibitor molecules continuously formed a protective barrier at the metal-solution interface. Thus, the active sites on the surface of carbon steel during the first 12 hours were almost completely occupied by the inhibitor, minimizing the corrosive process ${ }^{39}$.

After 24 hours of immersion there is a slight decrease in resistance to corrosion. This behavior is even more evident when looking at Figure 13, which shows the efficiency values in relation to the immersion time.

Through Figure 12 and Figure 13, it is observed that in 48 and 72 hours the decrease is more accentuated, which can be attributed to the gradual process of desorption and also the degradation of the inhibitor molecules ${ }^{40}$. Thus, there was an increase in the area exposed to the acidic media, maximizing corrosion in unprotected $\operatorname{sites}^{39}$.

Yetri et al. (2018) also evaluated a cocoa residue, specifically the cacao peel extract, and they observed a reduction in inhibition efficiency with increasing immersion time. These authors identified the biggest efficiency with $2.5 \%$ extract during 48 hours of immersion in $\mathrm{HCl} 1.5 \mathrm{M}$. They suggested that after this period the inhibitor molecules desorption occurred ${ }^{14}$.
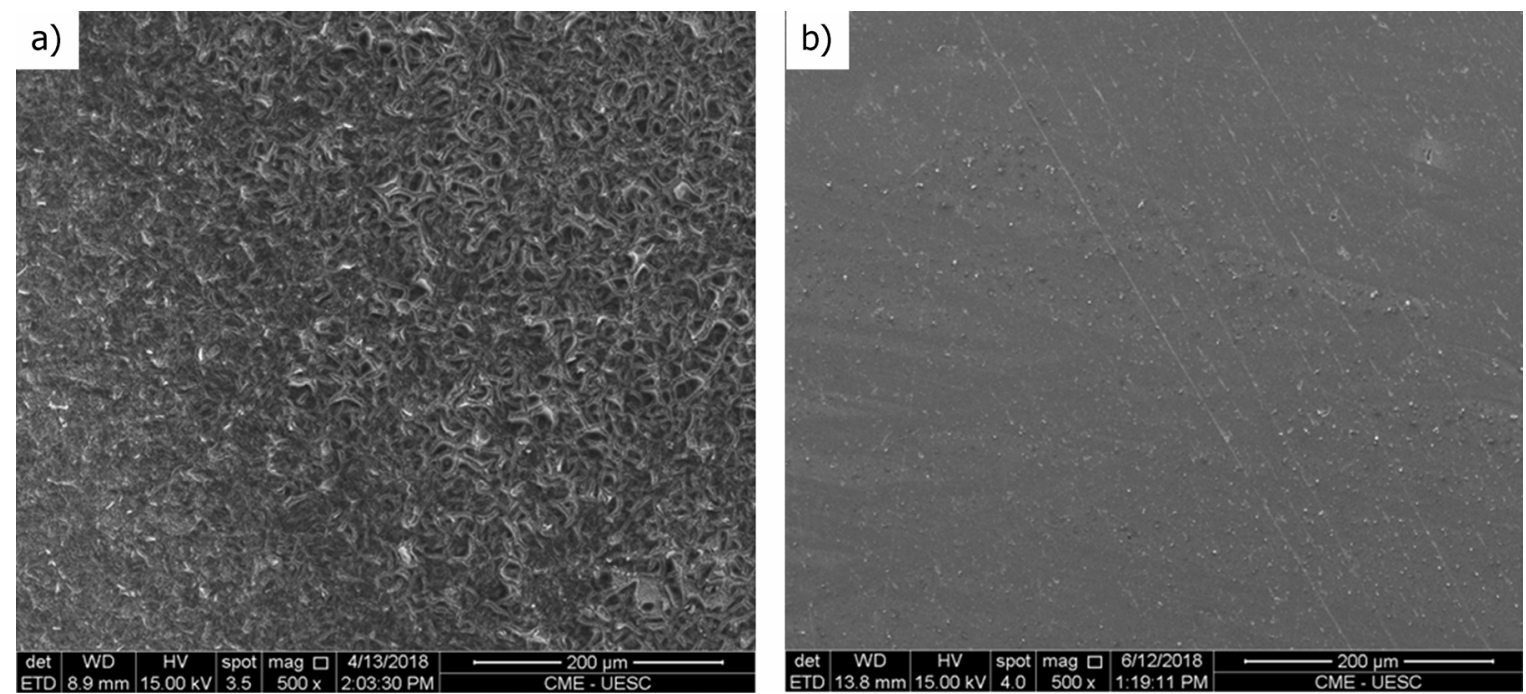

Figure 11. SEM micrographs of SAE 1008 carbon steel surface after immersion in the electrolyte, in the absence (a) and in the presence of inhibitor (b).
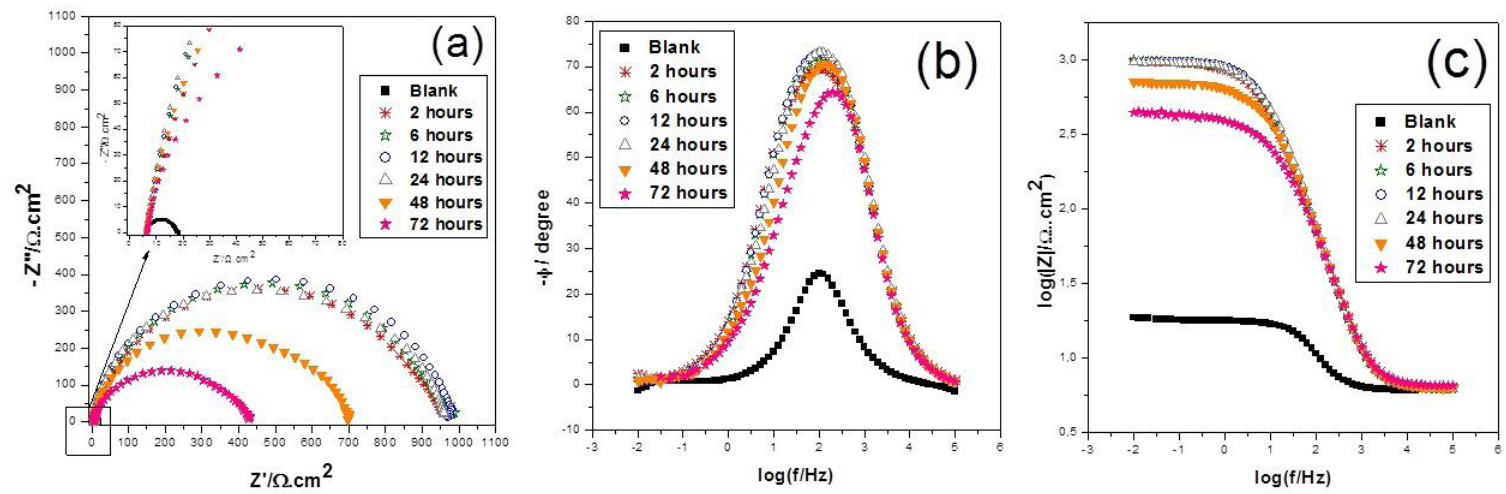

Figure 12. Nyquist (a) and Bode plots, containing the phase angle (b) and logarithm of the impedance modulus (c), for the carbon steel in the presence of $1.77 \mathrm{gL}^{-1}$ of the cocoa bean shell powder at different immersion times. 


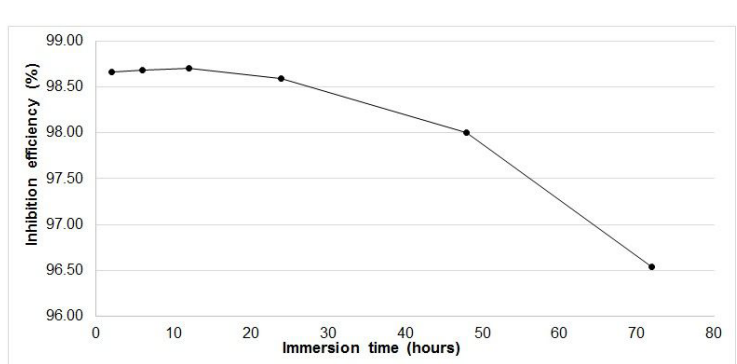

Figure 13. Corrosion inhibition efficiency at different immersion times in $0.5 \mathrm{~mol} \mathrm{~L}^{-1} \mathrm{HCl}$ solution.

Santos et al. (2020) verified the corrosion inhibition efficiency in relation to the immersion time in the presence of the green inhibitor from the palm kernel cake powder ${ }^{41}$. These researchers observed a greater efficiency in the time of 12 hours and after 24 hours they also reported a decrease. They suggested that the desorption of the inhibitory molecules may be associated with the weak interactions between the inhibitor and the metallic surface resulting from the physical adsorption mechanism of species. In the present study it was also found that the adsorption process that occurred was that of physisorption (as presented in topic 3.6), corroborating the argument presented by Santos et al. (2020) ${ }^{41}$. Thus, in longer immersion times, probably the weak interactions between the adsorbate and the metallic substrate began to rupture, favoring desorption.

\subsection{Cocoa bean shell corrosion inhibitor economic evaluation}

Initially, the mass balance was carried out in the production process to verify its efficiency. From the mass balances, it was found that the production process of the corrosion inhibitor has an efficiency of $12.0 \%$, in other words, for each kilogram of waste introduced in the feed stream, 120 grams of corrosion inhibitor is produced. The greatest loss of material was observed in the sieving stage (69\%). This significant loss of mass occurred due to the high quantity of larger particles in the output stream of the milling process. From these results, we can see that the sieving step contributed to the low efficiency of the process since most of the solids were retained in the undesired sieves. Therefore, it is recommended to use a longer milling time or another type of mill; however, this evaluation was not the aim of this work, since this supposed change would probably lead to alteration of properties of the corrosion inhibitor. An alternative to the large amounts of solid residues was explored by Lessa et al. (2018), where the researchers evaluated the production of antioxidants from this material by solid-state fermentation method ${ }^{19}$. However, it is a process that requires time and specific reagents, which can be expensive for our investigation. To overcome these limitations and reuse the entire cocoa bean shell residue as an inhibitor, our group is investigating - for future works the production of an inhibitor from the solid residue extract.

Given these results, to produce $1.0 \mathrm{~kg}$ of corrosion inhibitor we need $8.4 \mathrm{~kg}$ of residue in the process feed stream. As the system of our laboratory has this capacity of operation, this step was carried out in a single batch. Table 8 shows the costs of this production process.
Table 8. Laboratory production costs for the corrosion inhibitor.

\begin{tabular}{cc}
\hline Item & Cost $\left(\mathrm{USD} \mathrm{kg}^{-1}\right)$ \\
\hline Transport & 1.94 \\
\hline Drying process & 0.72 \\
\hline Grinding process & 0.02 \\
\hline Sieving process & 0.01 \\
\hline Total & 2.69 \\
\hline
\end{tabular}

Comparing Table 8 and Table 2, we can see that the production cost of $1 \mathrm{~kg}$ of cocoa shell powder is much lower than commercial corrosion inhibitors. Even though Table 2 contains other costs that were not estimated for the residue, such as profits and taxes, the studied inhibitor is 48-616 times cheaper than traditional corrosion inhibitors. These values justify its use even at a higher concentration than the concentrations recommended for commercial inhibitors.

\section{Conclusions}

The electrochemical impedance data showed that, with the increasing concentration of inhibitor, there was an increase in the values of corrosion inhibition efficiency, whose maximum value was $97.92 \%$ at an optimal content of $1.77 \mathrm{~g} \mathrm{~L}^{-1}$. The gravimetric results confirmed the electrochemical results.

The potentiodynamic polarization curves demonstrated that the cocoa residue is a mixed type inhibitor, hindering both anodic and cathodic reactions.

The SVET results showed that the corrosion inhibitor reduces both anodic and cathodic ionic activity.

The thermodynamic study showed that the molecules present in cocoa bean shell powder were physically adsorbed on the surface of the carbon steel (physisorption), probably due to the interaction of heteroatoms present in the FTIR (carbon, oxygen, and nitrogen) spectrum. The adsorption process of the molecules follows the Langmuir isotherm model, which assumes that each site is occupied by only one adsorbed molecule.

Through economic evaluation, the corrosion inhibitor from cocoa bean shell has excellent economic viability compared to the commercial inhibitors, which are expensive and often toxic.

Thus, from electrochemical and gravimetric results, it can be inferred that the cocoa bean shell powder has the potential to be used as a corrosion inhibitor for SAE 1008 carbon steel in $0.5 \mathrm{~mol} \mathrm{~L}^{-1} \mathrm{HCl}$ solution.

\section{Acknowledgments}

This work was supported by the Pró-Reitoria de Pesquisa da Universidade Federal de Minas Gerais (PRPq/UFMG). Authors would like to acknowledge to CAPES and CNPq for financial support, the BIOMA (Environment and Bioenergy Group) of State University of Santa Cruz (BA, BR) for FTIR analysis, LAMMA (Environment and Materials Laboratory) of State University of Santa Cruz (BA, BR) for support, CME (Electronic Microscopy Center) of State University of Santa Cruz (BA, BR) for SEM images, LEC (Electrochemical and Corrosion Laboratory) of University of São Paulo (SP, BR) for SVET analysis, USIMINAS (MG, BR) for the steel 
samples and Mendoá Chocolates (Riachuelo Farm - BA, BR) for cocoa bean shell.

\section{References}

1. Santos ECD, Cordeiro R, Santos M, Rodrigues PRP, Singh A, D'Elia E. Barley agro-industrial residues as corrosion inhibitor for mild steel in $1 \mathrm{~mol} \mathrm{~L}^{-1} \mathrm{HCl}$ solution. Mater Res. 2019;22(2):1-14.

2. Singh A, Ebenso EE, Quraishi MA. Corrosion inhibition of carbon steel in $\mathrm{HCl}$ solution by some plant extracts. Int J Corros. 2012;2012:1-20

3. Verma C, Ebenso EE, Bahadur I, Quraishi MA. An overview on plant extracts as environmental sustainable and green corrosion inhibitors for metals and alloys in aggressive corrosive media. J Mol Liq. 2018;266:577-90.

4. Azzaoui K, Mejdoubi E, Jodeh S, Lamhamdi A, RodriguezCastellón E, Algarra M, et al. Eco friendly green inhibitor Gum Arabic (GA) for the corrosion control of mild steel in hydrochloric acid medium. Corros Sci. 2017;129:70-81.

5. Raja PB, Sethuraman MG. Natural products as corrosion inhibitor for metals in corrosive media - a review'. Mater Lett. 2008;62(1):113-6.

6. Nouri PM, Attar MM. An imidazole-based antifungal drug as a corrosion inhibitor for steel in hydrochloric acid. Chem Eng Commun. 2016;203(4):505-15.

7. Fouda AS, Al-Sarawy AA, El-Katori EE. Pyrazolone Derivatives as Corrosion Inhibitors for C-Steel in hydrochloric acid solution. Desalination. 2006;201(1-3):1-13.

8. Obot IB, Meroufel A, Onyeachu IB, Alenazi A, Ahmad AS. Corrosion inhibitors for acid cleaning of desalination heat exchangers: progress, challenges and future perspectives. J Mol Liq. 2019;296:711-60.

9. Al-Sarawy AA, Fouda AS, El-Dein WAS. Some thiazole derivatives as corrosion inhibitors for carbon steel in acidic medium. Desalination. 2008;229(1-3):279-93.

10. Chugh B, Singh AK, Chaouiki A, Salghi R, Thakur S, Pani B. A comprehensive study about anti-corrosion behaviour of pyrazine carbohydrazide: gravimetric, electrochemical, surface and theoretical study. J Mol Liq. 2020;299:112-60.

11. Rocha JC, Gomes JACP, D'Elia E. Aqueous extracts of mango and orange peel as green inhibitors for carbon steel in hydrochloric acid solution. Mater Res. 2014;17(6):1581-7.

12. Barreto LS, Tokumoto MS, Guedes IC, Melo HG, Amado F, Capelossi VR. Study and assessment of the efficiency of the cocoa bark extracted from the Theobroma Cacao as an inhibitor of the corrosion of carbon steel in substitution of benzotriazole. Mater Res. 2018;21(1):1-9.

13. Pedroza-Periñán DE, Villalobos-Vásquez MA, Meza-Castellar PJ, Paz-Astudillo IC. Evaluation of Theobroma Cacao pod husk extracts as corrosion inhibitor for carbon steel. CT\&F. 2016;6(3):147-56

14. Yetri Y, Gunawarman, Emriadi, Jamarun N. Theobroma cacao peel extract as the eco-friendly corrosion inhibitor for mild steel. In: Aliofkhazraei M, editor. Corrosion inhibitors, principles and recent applications. Rijeka: IntechOpen; 2018. p. 200-23. https://doi.org/10.5772/intechopen.73263

15. Barreto LS, Tokumoto MS, Guedes IC, Melo HG, Amado F, Capelossi VR. Evaluation of the anticorrosion performance of peel garlic extract as corrosion inhibitor for Astm 1020 carbon steel in acidic solution. Revista Matéria. 2017;22(3):1-14.

16. Santos AM, Almeida TF, Cotting F, Aoki IV, Melo HG, Capelossi VR. Evaluation of castor bark powder as a corrosion inhibitor for carbon steel in acidic media. Mater Res. 2017;20:492-505.

17. Moreira IMDV, Vilela LF, Santos C, Lima N, Schwan RF. Volatile compounds and protein profiles analyses of fermented cocoa beans and chocolates from different hybrids cultivated in Brazil. Food Res Int. 2018;109:196-203.
18. Rojo-Poveda O, Barbosa-Pereira L, Zeppa G, Stévigny C. Cocoa bean shell: a by-product with nutritional properties and biofunctional potential. Nutrients. 2020;12(4):1123-51.

19. Lessa OA, Reis NDS, Leite SGF, Gutarra MLE, Souza AO, Gualberto SA, et al. Effect of the solid state fermentation of cocoa shell on the secondary metabolites, antioxidant activity, and fatty acids. Food Sci Biotechnol. 2018;27(1):107-13.

20. Okiyama DCG, Navarro SLB, Rodrigues CEC. Cocoa shell and its compounds: applications in the food industry. Trends Food Sci Technol. 2017;63:103-12.

21. Hashimoto JC, Lima JC, Celeghini RMS, Nogueira AB, Efraim P, Poppi RJ, et al. Quality control of commercial cocoa beans (Theobroma cacao L.) by near-infrared spectroscopy. Food Anal Methods. 2018;11(5):1510-7.

22. Ahmad F, Daud WMAW, Ahmad MA, Radzi R, Azmi AA. The effects of $\mathrm{CO}_{2}$ activation, on porosity and surface functional groups of cocoa (Theobroma cacao) - shell based activated carbon. J Environ Chem Eng. 2013;1(3):378-88.

23. ASTM: American Society for Testing and Materials. ASTM Standard G1-03 - Standard practice for preparing, cleaning, and evaluating corrosion test specimens. West Conshohocken: ASTM Standards; 2003. p. 15-21.

24. Obuge AM, Evbuomwan OB. Adsorption of methylene blue onto activated carbon impregnated with $\mathrm{KOH}$ using cocoa shell. Int J Eng Res. 2014;2(10):11-8.

25. Pua FL, Sajab MS, Chia CH, Zakaria S, Rahman IA, Salit MS. Alkaline-treated cocoa pod husk as adsorbent for removing methylene blue from aqueous solutions. J Environ Chem Eng. 2013;1(3):460-5.

26. Fioresi F, Vieillard J, Bargougui R, Bouazizi N, Fotsing PN, Woumfo ED, et al. Chemical modification of the cocoa shell surface using diazonium salts. J Colloid Interface Sci. 2017;494:92-7.

27. Ituen E, Akaranta O, James A, Sun S. Green and sustainable local biomaterials for oilfield chemicals: Griffonia Simplicifolia extract as steel corrosion inhibitor in hydrochloric acid. Sustain Mater Technol. 2017;11:12-8.

28. Abd El-Lateef HM, Abu-Dief AM, Mohamed MAA. Corrosion inhibition of carbon steel pipelines by some novel Schiff base compounds during acidizing treatment of oil wells studied by electrochemical and quantum chemical methods. J Mol Struct. 2017;1130:522-42.

29. Benarioua M, Mihi A, Bouzeghaia N, Naoun M. Mild steel corrosion inhibition by parsley (Petroselium Sativum) extract in acidic media. Egypt J Pet. 2019;28:155-9.

30. Hussin MH, Rahim AA, Ibrahim MNM, Brosse N. The capability of ultrafiltrated alkaline and organosolv oil palm (Elaeis Guineensis) fronds lignin as green corrosion inhibitor for mild steel in $0.5 \mathrm{M} \mathrm{HCl}$ solution. Measurement. 2016;78:90-103.

31. Mourya P, Banerjee S, Singh MM. Corrosion inhibition of mild steel in acidic solution by Tagetes erecta (Marigold flower) extract as a green inhibitor. Corros Sci. 2014;85:352-63.

32. El Bakri Y, Guo L, Anouar EH, Essassi EM. Electrochemical, DFT and MD simulation of newly synthesized triazolotriazepine derivatives as corrosion inhibitors for carbon steel in $1 \mathrm{M} \mathrm{HCl}$. J Mol Liq. 2019;274:759-69.

33. Revie RW, Uhlig HH. Corrosion and corrosion control: an introduction to corrosion science and engineering. 4th ed. Hoboken: Wiley-Interscience; 2008.

34. Bastos AC, Quevedo MC, Karavai OV, Ferreira MGS. Review: on the application of the Scanning Vibrating Electrode Technique (SVET) to corrosion research. J Electrochem Soc. 2017;164(14):973-90.

35. Dada AO, Olalekan AP, Olatunya AM, Dada O. Langmuir, Freundlich, Temkin and Dubinin-Radushkevich Isotherms studies of equilibrium sorption of $\mathrm{Zn}^{2+}$ unto phosphoric acid modified Rice Husk. J Appl Chem. 2012;3(1):38-45.

36. Fateh A, Aliofkhazraei M, Rezvanian AR. Review of corrosive environments for copper and its corrosion inhibitors. Arab J Chem. 2020;13(1):481-544. 
37. Santana CA, Da Cunha JN, Rodrigues JGA, Greco-Duarte J, Freire DMG, D'Elia E. Aqueous extracts of the castor beans as a corrosion inhibitor of mild steel in $\mathrm{HCl}$ media. J Braz Chem Soc. 2020;31(6): 1225-38.

38. El-Awady AA, Abd-El-Nabey BA, Aziz SG. Kinetic-thermodynamic and adsorption isotherms analyses for the inhibition of the acid corrosion of steel by cyclic and open-chain amines. $\mathrm{J}$ Electrochem Soc. 1992;139(8):2149-54.

39. Salinas-Solano G, Porcayo-Calderon J, Escalera LMM, Canto J, Casales-Diaz M, Sotelo-Mazon O, et al. Development and evaluation of a green corrosion inhibitor based on rice bran oil obtained from agro-industrial waste. Ind Crops Prod. 2018;119:111-24.

40. Ji G, Dwivedi P, Sundaram S, Prakash R. Aqueous extract of Argemone mexicana roots for effective protection of mild steel in an $\mathrm{HCl}$ environment. Res Chem Intermed. 2016;42(2):439-59.

41. Santos AM, Aquino IP, Cotting F, Aoki IV, Melo HG, Capelossi VR. Evaluation of palm kernel cake powder (Elaeis Guineensis Jacq.) as corrosion inhibitor for carbon steel in acidic media. Met Mater Int. 2020;27:1519-30.' 